\title{
Article \\ Highly Sensitive and Selective Copper (II)-Catalyzed Dual-DNAzyme Colorimetric Biosensor Based on Exonuclease III-Mediated Cyclical Assembly
}

\author{
Baiqiang Zhai ${ }^{1,2}$, Kunlun Huang ${ }^{2}$, Hongtao Wang ${ }^{1}$, Dongmin Su ${ }^{1,3, *}$ and Yuancong $\mathrm{Xu}^{2,4, * \mathbb{C}}$ \\ 1 Henan Railway Food Safety Management Engineering Technology Research Center, \\ Zhengzhou Railway Vocational \& Technology College, Zhengzhou 451460, China; \\ zhaibaiqiang@zzrvtc.edu.cn (B.Z.); 10554@zzrvtc.edu.cn (H.W.) \\ 2 Beijing Laboratory for Food Quality and Safety, College of Food Science and Nutritional Engineering, \\ China Agricultural University, Beijing 100083, China; hk1009@163.com \\ 3 College of Food and Bioengineering, Zhengzhou University of Light Industry, Zhengzhou 450002, China \\ 4 Beijing Key Laboratory of Environmental and Viral Oncology, Faculty of Environment and Life, \\ Beijing University of Technology, Beijing 100124, China \\ * Correspondence: dongminsu@haut.edu.cn (D.S.); xuyuancong@bjut.edu.cn (Y.X.); \\ Tel.: +86-0371-86608028 (D.S.); +86-010-67396139 (Y.X.)
}

check for

updates

Citation: Zhai, B.; Huang, K.; Wang, H.; Su, D.; Xu, Y. Highly Sensitive and Selective Copper (II)-Catalyzed Dual-DNAzyme Colorimetric Biosensor Based on Exonuclease III-Mediated Cyclical Assembly. Catalysts 2021, 11, 1352. https:// doi.org/10.3390/catal11111352

Academic Editor: Omer Yehezkeli

Received: 18 October 2021

Accepted: 8 November 2021

Published: 11 November 2021

Publisher's Note: MDPI stays neutral with regard to jurisdictional claims in published maps and institutional affiliations.

Copyright: (c) 2021 by the authors. Licensee MDPI, Basel, Switzerland. This article is an open access article distributed under the terms and conditions of the Creative Commons Attribution (CC BY) license (https:// creativecommons.org/licenses/by/ $4.0 /)$.

\begin{abstract}
Cu-DNAzyme" and "G4-DNAzyme" were used to develop a "turn-off" dual-DNAzyme colorimetric biosensor, which could be used to detect $\mathrm{Cu}^{2+}$ by employing exonuclease III-mediated cyclical assembly (EMCA). EMCA was based on the cleavage activity of $\mathrm{Cu}^{2+}$ to transfer the linkage sequences of the substrate strand and enzyme strand into the transition sequence. The horseradish peroxidase (HRP)-mimicking activity of the G4-DNAzyme was lost after binding with the complementary transition sequence and was hydrolyzed by Exo III. These results demonstrate that the proposed colorimetric biosensor was an effective method for ultradetection of trace metals in a high original signal background. Due to the high sensitivity of the biosensor, the limit of detection (LOD) of $\mathrm{Cu}^{2+}$ is $0.16 \mathrm{nM}$. This design offers a general purpose platform that could be applied for the detection of any metal ion target through adjustment of metal-dependent DNA-cleaving DNAzymes, which is of great significance for the rapid determination of food safety.
\end{abstract}

Keywords: copper ions; dual DNAzyme; exonuclease III-mediated cyclical assembly; biosensor

\section{Introduction}

Copper $(\mathrm{Cu})$ is one of the most abundant trace elements in living organisms and is a common metal worldwide, and is widely utilized in agricultural and industrial fields [1]. Although copper is an important element, excessive intake could contribute to Parkinson's, Wilson's, and Alzheimer's diseases and anemia [2]. The World Health Organization (WHO) and the European Union (EU) have recommended the highest copper concentration as $2 \mathrm{mg} / \mathrm{L}$ in human drinking water, while the U.S. Environmental Protection Agency (EPA) and the Ministry of Health in China have recommended the highest copper concentration as $1 \mathrm{mg} / \mathrm{L}$ in human drinking water.

The accurate measurement of $\mathrm{Cu}^{2+}$ with high selectivity and sensitivity is an important problem and has attracted increasing attention in recent years. Traditional analytical techniques for sensing $\mathrm{Cu}^{2+}$ depend upon expensive analytical equipment $[3,4]$, but the onsite rapid detection of these methods is limited due to their complex sample pretreatments and high operating cost. Recently, biosensor methods that have shown good sensitivity and selectivity have been widely used in the rapid detection of $\mathrm{Cu}^{2+}$, such as fluorescent biosensors [5,6], plasmonic biosensors [7,8], colorimetric biosensors [9,10], and electrochemical biosensors [11-13]. By comparing the aforementioned biosensors, $\mathrm{Cu}^{2+}$-cleaving DNAzyme (Cu-DNAzyme) is the signal recognition and transition of choice, nucleic acid 
amplification is the best method to increase sensitivity, and colorimetric analysis is the most convenient option.

Single-stranded DNA can bind to specific target molecules and exhibit catalytic activities, performing similarly to nucleic acid enzymes and protein enzymes under sequencedependent tertiary structures [14]. Nucleic acid enzymes, including ribozymes (catalytic RNA) and deoxyribozymes (catalytic DNA or DNAzymes), can effectively catalyze RNA or DNA cleavage and have been frequently applied in sensing applications, such as $\mathrm{Cu}^{2+}[6,12,15], \mathrm{Pb}^{2+}[16-18], \mathrm{Zn}^{2+}[19,20], \mathrm{Mg}^{2+}$ [21], $\mathrm{UO}_{2}{ }^{2+}$ [22], and $\mathrm{Cr}^{3+}$ [23]. These methods render DNAzymes a terrific intermediary for sensing metal ions, and they have shown improved status compared with the normal direct detection method. The $\mathrm{Cu}$ DNAzyme is formed from two DNA strands, which include substrate and enzyme. In the presence of $\mathrm{Cu}^{2+}$, the substrate strand can be cleaved into two fragments, which can then be used in nucleic acid amplification. By combining cleavage and amplification, a high sensitivity method can be designed for the detection of $\mathrm{Cu}^{2+}$.

Currently, nucleic acid amplification has been developed for the detection of metal ions in view of the transformation from metal ions to nucleic acids. Metal ion-mediated DNAzymes with cleavage activity are more suited for ssDNA amplification, such as strand displacement amplification (SDA) [18,19,24], rolling circle amplification (RCA) $[25,26]$, and hybridization chain reaction (HCR) $[20,23]$. All of these methods are DNA replication isothermal technologies that have traditionally used specific primer sequences to generate multiple copies of a sequence library by DNA polymerase. However, there are some disadvantages with respect to template processing, primer design, reaction optimization, enzyme dependence, and sensitivity improvement. Considering the special structure of the Cu-DNAzyme, two DNA strands can be merged into one strand without disrupting its cleavage activity. Then, the combination of new Cu-DNAzyme and exonuclease (Exo) III strategies [27] can resolve the above problems. This paper proposes the concept of cyclic "hybridization-hydrolyzation" in order to achieve the detection of $\mathrm{Cu}^{2+}$. Particularly for trace detection, which still faces challenges, our concept is able to meet this demand.

$\mathrm{Cu}$-biosensors can also be classified, according to the characteristics of the signals, into turn-on [28] and turn-off [29] biosensors. For the turn-on biosensor, the signal intensity increases with increasing amounts of the target. Due to its strong specificity but low sensitivity, it is not appropriate for trace detection. For the turn-off biosensor, the signal intensity decreases with increasing amounts of the target. It can still maintain stable detection for low concentration targets, becoming the preferred strategy for trace detection. Colorimetric biosensors have the advantages of being convenient, inexpensive, and visible and have been widely used in turn-off biosensors. One of the typical representatives of colorimetric elements is G-quadruplex DNAzymes (G4-DNAzymes) [30]. The G4-DNAzymes exhibit superior peroxidase-like activity in the presence of hemin and are able to catalyze $\mathrm{H}_{2} \mathrm{O}_{2}$-mediated oxidation of 2,2'-azino-bis-(3-ethylbenzthiazoline-6-sulphonate) (ABTS), producing a green product (free-radical cation $\mathrm{ABTS}^{\bullet+}$ ) with a maximal absorption signal at a wavelength of $\sim 419 \mathrm{~nm}$. The integration of Cu-DNAzyme and G4-DNAzyme will further simplify the detection of $\mathrm{Cu}^{2+}$. It also combines the advantages of specificity for signal recognition and sensitivity for signal visibility analysis.

In this paper, a highly sensitive "turn-off" dual DNAzyme colorimetric biosensor based on exonuclease III-mediated cyclical assembly (EMCA) for selecting and quantifying $\mathrm{Cu}^{2+}$ was developed. The principle of the proposed biosensor is depicted in Figure 1. As shown in Figure 1A, CUzyme comprises three parts: substrate strand (blue), linker sequence (red), and enzyme strand (green). The orange site in the substrate strand was the cleavage site. In the presence of $\mathrm{Cu}^{2+}, \mathrm{CUzyme}$ was activated to irreversibly cleave the substrate strand at the cleavage site, producing two kinds of products. Due to its less stable intermolecular duplex structure, the cleaved substrate strands (blue, called the waste product) were released. For the remainder of CUzyme (called the first product), the spatial structure caused changes, forming a structured enzyme/linker complex with 
a single strand tail, which would continue to participate in the subsequent reaction. The red tail is a complementary sequence of part of the G4-DNAzyme.

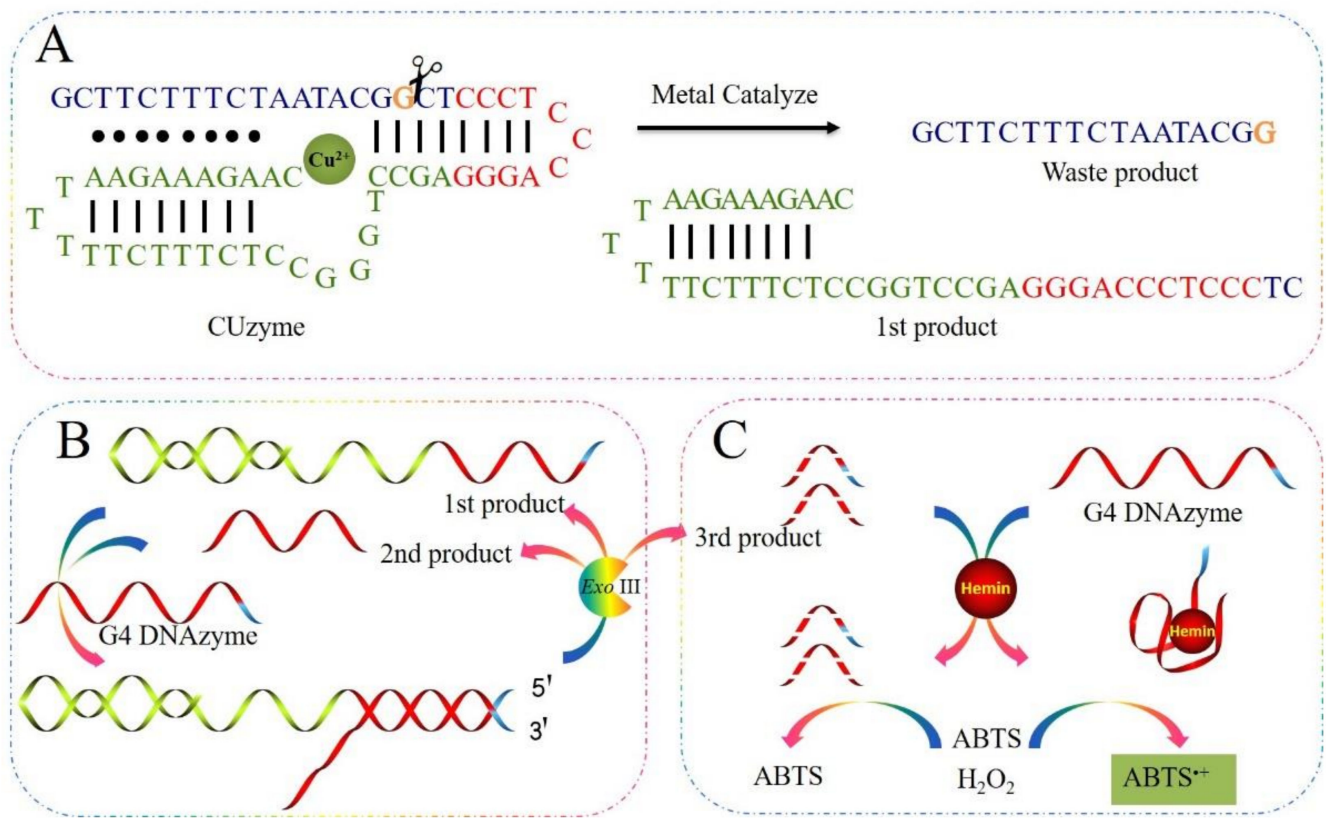

Figure 1. Principles of the "turn-off" dual-DNAzyme colorimetric biosensor for $\mathrm{Cu}^{2+}$ ions. (A) Recognition of $\mathrm{Cu}^{2+}$; (B) EMCA; (C) color reaction.

The details of the EMCA are shown in Figure 1B. The red tail could effectively hybridize with the G4-DNAzyme, forming a double strand complex with a blunt end. Then, the 3'-termini of G4-DNAzymes in the complex are hydrolyzed by Exo III, and this stimulates the release of the first product, the residual G4-DNAzyme (called the second product), and free bases (called the third product). The first product can further hybridize repeatedly with a new G4-DNAzyme, generating a cycle of hybridization-hydrolyzation. Due to the repeat "AGGG" in the G4-DNAzyme, the second product could further hybridize with the first product. Then, the introduction of the recessed $3^{\prime}$-termini could still trigger a hydrolyzation reaction by Exo III and the subsequent production of the abundant third product. The color reaction of the "turn-off" dual DNAzyme colorimetric biosensor is shown in Figure 1C. The G4-DNAzyme folds into many G-quadruplex structures that could combine with hemin to form an HRP-like DNAzyme, resulting in an increase in the absorbance signal due to an increased amount of green-colored ABTS ${ }^{\bullet+}$. However, when $\mathrm{Cu}^{2+}$ ions are added to the complex, the G4-DNAzyme is hydrolyzed to a free base by Exo III. As a result, the biosensor has no absorbance signal and is colorless.

In summary, this report describes the construction of a "turn-off" dual DNAzyme colorimetric biosensor that combines the amplification features of EMCA with fluorescence detection by employing the G4-DNAzyme. This design offers a general purpose platform that could be applied for the detection of any other metal ion target through the adjustment of the metal ion-mediated DNAzyme, which is of great significance for the development of rapid detection technology in food safety.

\section{Results}

\subsection{Feasibility of the Colorimetric Biosensor Based EMCA}

This report describes the construction of a "turn-off" dual DNAzyme colorimetric biosensor that combines Cu-DNAzyme, EMCA, and G4-DNAzyme. The Cu-DNAzyme was employed as the recognition element of biosensor to achieve high specificity. EMCA amplification was developed to achieve signal reduction in biosensors. The G4-DNAzyme, as the detection element, is more applicable to the visual analysis of biosensor. As a result, 
the success of our colorimetric biosensor was based on three dimensions: effective cleavage by $\mathrm{Cu}^{2+}$, effective hydrolysis by Exo III, and color reaction of G4-DNAzyme.

EMCA is driven by a free single strand tail. However, the tail could not be released unless $\mathrm{Cu}$-DNAzyme was cleaved by $\mathrm{Cu}^{2+}$. Thus, the ability and efficiency of cleavage is one of the most important factors of the biosensor. In order to certify cutting efficiency, the experiments were carried out at different times. The length of the carboxyfluorescein (FAM)-labeled substrate (FAM-Cu-S) was $23 \mathrm{nt}$. In the presence of $\mathrm{Cu}^{2+}, \mathrm{FAM}-\mathrm{Cu}-\mathrm{S}$ was cleaved to $17 \mathrm{nt}$. As shown in Figure 2A, with increasing treatment time, the $23 \mathrm{nt}$ and $17 \mathrm{nt}$ bands gradually became shallow and dark, respectively. These results indicated that cutting efficiency increased with time and reached a peak after $10 \mathrm{~min}$. Based on the brightness of Lane 1, the cleavage rate was quantified by Image Lab 4.1 software. As shown in Figure 2B, the cleavage rate was above $50 \%$ after cutting for $2 \mathrm{~min}$ and above $80 \%$ after cutting for $10 \mathrm{~min}$. Considering the timeliness of the overall reaction, $5 \mathrm{~min}$ was selected as the final cutting time.
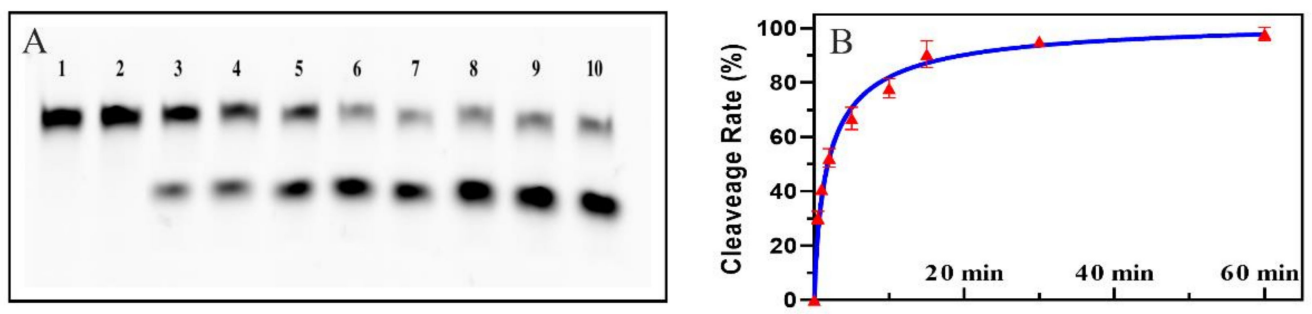

Figure 2. Cleavage rate of $\mathrm{Cu}^{2+}$ at different reaction times. (A) The results of dPAGE. Lanes 1-10: 0, $10 \mathrm{~s}, 30 \mathrm{~s}, 1 \mathrm{~min}, 2 \mathrm{~min}, 5 \mathrm{~min}, 10 \mathrm{~min}, 15 \mathrm{~min}, 30 \mathrm{~min}$, and $60 \mathrm{~min}$. (B) Cleavage rate.

EMCA was designed to breakdown the G4-DNAzyme. Moreover, the sustainability of EMCA was dependent on Exo III. Exo III displayed the ability to catalyze the stepwise digestion of mononucleotides from the recessed $3^{\prime}$ terminus or the blunt part of the doublestranded DNA in order to recycle the target. Since signal reduction relied on Exo III, it was important to verify the hydrolysis. Due to the special G-quadruplex structure of the G4-DNAzyme, the complementary strand was used to verify the hydrolyzation reaction. Based on EMCA, G4-C and G4-M were designed to simulate the hybridization of the first product and the G4-DNAzyme. When FAM-labeled G4-C and G4-M meet, they bind to each other and form double-stranded DNA. Under the hydrolyzation reaction, Exo III could catalyze the removal of nucleotides from FAM-labeled G4-C in the $3^{\prime}$ to $5^{\prime}$ direction. As shown in Figure S1, a significant band in Lane 1 could be observed in the presence of FAM-labeled G4-C, and ladder bands were observed in Lane 2, indicating that FAMlabeled G4-C was degraded and generated different lengths of ssDNA. This phenomenon displayed a straightforward conclusion that G4-DNAzyme could also be degraded during EMCA, which inhibited color reactions.

Green signal of biosensor came from $\mathrm{ABTS}^{\bullet+}$, which was produced by the oxidation of ABTS with G4-DNAzyme. G4-DNAzyme is a G-rich sequence that has four continuous "GGG", forming a stable G-quadruplex structure. Moreover, G4-DNAzyme was hydrolyzed by Exo III to different lengths of fragment. False-positive results might be caused if the fragment remained the HRP-mimicking activity. In order to avoid false-positives of the second product, the color reaction was tested by different lengths of G4-DNAzymes. G4-1 and G4-2 were designed by removing one and two "GGG", respectively. G4-T-1 and G4-T-2 were designed to block one and two "GGG" in G4-DNAzyme, respectively. As shown in Figure S2, absorbance experiments under several conditions were carried out to demonstrate the feasibility of the biosensor. An intact G4-DNAzyme had a strong absorbance intensity and green color in the reaction. The absorbance intensity decreased in G4-1, which means that the deletion of "GGG" might not have a devastating impact on the G-quadruplex structure. However, G4-2 had no absorbance intensity, which means that G4-2 had no HRP-mimicking activity. When the G4-DNAzyme hybridizes with G4-T-1 or G4-T-2, the absorbance intensity can always be observed. This phenomenon explained 
why the HRP-mimicking activity of G4-DNAzyme would not be totally blocked by the complementary strand. These two results comprehensively demonstrated that Exo III was essential in EMCA.

\subsection{Develop and Optimize the Condition of the Biosensor}

By exploration, a "turn-off" dual DNAzyme colorimetric biosensor was developed for the detection of $\mathrm{Cu}^{2+}$ ions. Moreover, the typical biosensor was verified with and without $\mathrm{Cu}^{2+}$ ions. The negative control was the mixture of GUzyme, G4-DNAzyme, hemin system, and ABTS system. As shown in Figure 3A, very strong absorbance intensity and green color were obtained in the negative control. In the experimental group, the absorbance intensity was significantly decreased by the presence of $\mathrm{Cu}^{2+}$. The result indicated that G4-DNAzyme was successfully degraded. In order to achieve optimal sensing performance, the best detection parameters of the biosensor were determined. The absorbance change $A b_{0} / A b_{1}$ was used to evaluate the biosensor, where $A b_{0}$ and $A b_{1}$ were the absorbance intensities in the absence and presence of $\mathrm{Cu}^{2+}$, respectively. First, the concentration ratio of CUzyme to G4-DNAzyme was optimized. Figure 3B shows the effect of the concentration ratio on the $\mathrm{Ab}_{0} / \mathrm{Ab}_{1}$ value. With a fixed concentration of CUzyme, $\mathrm{Ab}_{0} / \mathrm{Ab}_{1}$ increased with increasing G4-DNAzyme. This indicated that G4-DNAzyme was successfully degraded in EMCA, and the degree of extinction was increased. However, when the ratio was over 1:2, the degree of extinction gradually decreased. This was caused by the strong background and limited hydrolysis of large amounts of G4-DNAzyme. As a result, the optimal concentration ratio of the CUzyme to the G4-DNAzyme was 1:2. Then, the concentration of Exo III was optimized. As shown in Figure 3C, $\mathrm{Ab}_{0} / \mathrm{Ab}_{1}$ increased gradually with increasing Exo III and then reached a maximum value at $4 \mathrm{U}$. This indicated that hydrolysis by Exo III reached the saturation point. As a result, the optimal concentration of Exo III was 4 U. Finally, the reaction time was also investigated. As shown in Figure $3 \mathrm{D}, \mathrm{Ab}_{0} / \mathrm{Ab}_{1}$ increased with increasing reaction time. When the reaction time was over $30 \mathrm{~min}, \mathrm{Ab}_{0} / \mathrm{Ab}_{1}$ increased slowly. We suspected that the $3^{\prime}$-terminus of most G4-DNAzymes and some second products might be degraded in $30 \mathrm{~min}$. The second products of varying length would be further degraded later. However, the rate of hydrolysis was slow due to the restriction of hybridization between the first product and the shorter second product. As a result, the optimal reaction time was $30 \mathrm{~min}$.
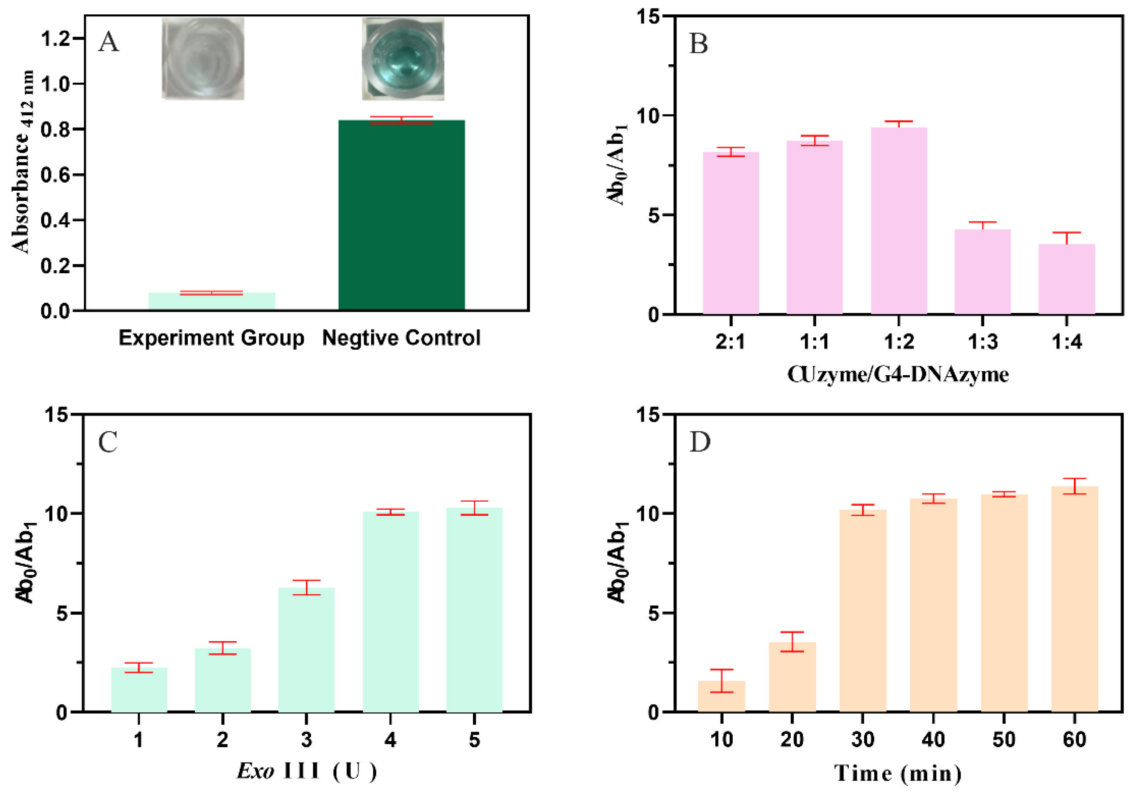

Figure 3. (A) Colorimetric biosensor detection with and without $\mathrm{Cu}^{2+}$ ions; optimization of the experimental conditions. (B) Ratio of CUzyme and G4-DNAzyme; (C) concentration of Exo III; (D) reaction time. The concentration of the $\mathrm{Cu}^{2+}$ is $300 \mathrm{nmol} / \mathrm{L}$. 


\subsection{Sensitivity for the Biosensor}

In order to evaluate the sensitivity of the established biosensor, a serial dilution of $\mathrm{Cu}^{2+}$ ranging from 0 to $300 \mathrm{nM}$ was used as a template for the optimized biosensor assays. Moreover, absorbance was measured at $412 \mathrm{~nm}$. As shown in the Figure 4A, absorbance intensity decreased quickly with an increasing $\mathrm{Cu}^{2+}$ ion concentration from 0 to $300 \mathrm{nM}$. This phenomenon reveals that the absorbance change was indeed due to the catalyzed cleavage activity of CUzyme. When the concentration was over $200 \mathrm{nM}$, the absorbance intensity basically had no variation. This result meant that almost all of the CUzyme could be cleaved, and almost all of the G4-DNAzyme could be hydrolyzed under high concentration conditions. The relationship between $\mathrm{Ab}_{0}-\mathrm{Ab}_{1}$ and $\mathrm{Cu}^{2+}$ concentrations is shown in Figure 4B. A good linear relationship was obtained from 1 to $200 \mathrm{nM}$ and is represented by $Y=0.003692 \times X+0.03380\left(R^{2}=0.9916\right)$, where $Y$ is $A b_{0}-A b_{1}$, and $X$ is the concentration $(\mathrm{nM})$. The LOD was calculated at $0.16 \mathrm{nM}$ on the basis of the average signal of the blank minus three times the standard deviation of the lowest analytical concentration. The detection limit of this approach was comparable to or even superior to other DNAzyme methods and more sensitive than the other analytical techniques for $\mathrm{Cu}^{2+}$ (Table S2).
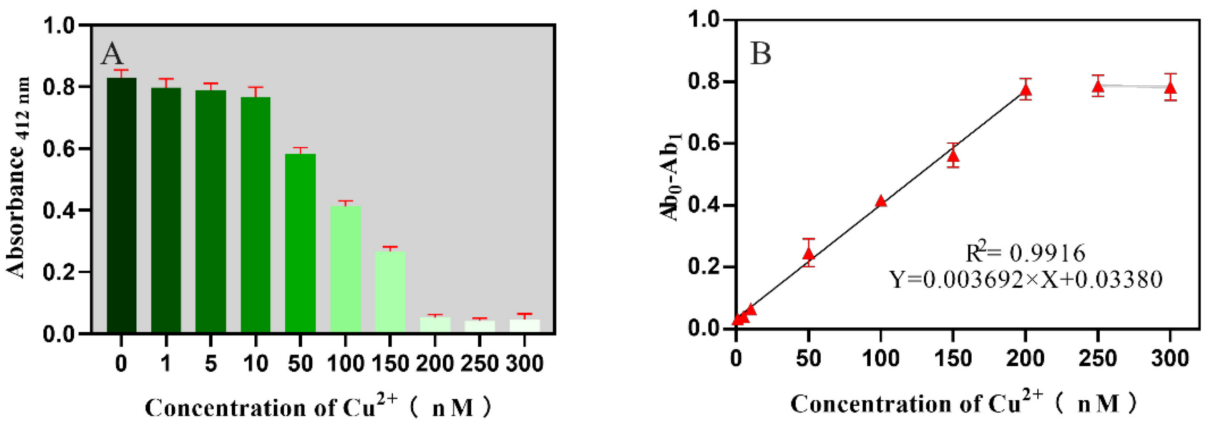

Figure 4. Sensitivity of the biosensor in response to various concentrations of $\mathrm{Cu}^{2+}$. (A) Absorbance intensity at $412 \mathrm{~nm}$; (B) the linear relationship between $A b_{0}-A b_{1}$ and the concentration.

\subsection{Selectivity for the Biosensor}

For practical samples, copper is often confused with other heavy metal ions, so a high specificity is necessary for a reliable assay. This biosensor was controlled by CUzyme, so it must have a high level of selectivity for $\mathrm{Cu}^{2+}$. In order to certify its high specificity, 10 other relevant metal ions $\left(\mathrm{Fe}^{3+}, \mathrm{Fe}^{2+}, \mathrm{Zn}^{2+}, \mathrm{Mg}^{2+}, \mathrm{Pb}^{2+}, \mathrm{Hg}^{2+}, \mathrm{Ca}^{2+}, \mathrm{Mn}^{2+}, \mathrm{Ni}^{2+}\right.$, and $\mathrm{K}^{+}$) were tested were tested in this biosensor. As shown in Figure 5, the absorbance value can reflect the specificity of the biosensor. With the exception of $\mathrm{Cu}^{2+}$, almost all metal ions induced little absorbance change, and selectivity was much higher. In summary, the absorbance signal reduction displayed high selectivity for $\mathrm{Cu}^{2+}$ ions with this biosensor.

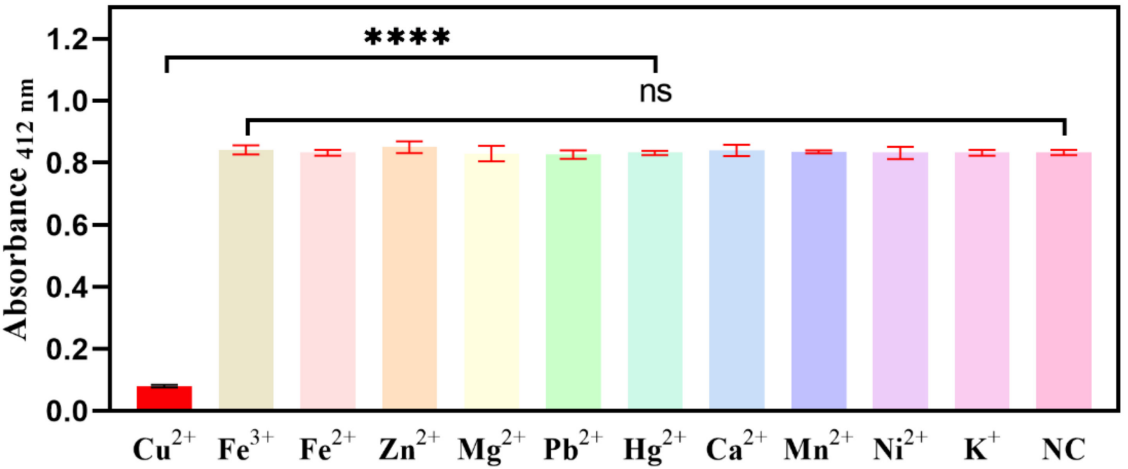

Figure 5. Specificity of the biosensor for different metal ions. The concentration of all of the metal ions is $300 \mathrm{nM}$. "ns": There was no significant difference; “****”: There was significant difference, $p$ value $<0.0001$. 


\subsection{Application of the Biosensor in Tap Water Samples}

Six kinds of tap water were analyzed by ICP-MS to ensure that there was no $\mathrm{Cu}^{2+}$ in them. In order to apply the proposed strategy to the highly sensitive detection of $\mathrm{Cu}^{2+}$ in environmental, water, soil, and food samples in the future, recovery experiments of $\mathrm{Cu}^{2+}$ were carried out in tap water. The water sample was processed with different concentrations of $\mathrm{Cu}^{2+}$ ions $(10 \mu \mathrm{M}, 20 \mu \mathrm{M}, 40 \mu \mathrm{M}, 60 \mu \mathrm{M}, 80 \mu \mathrm{M}$, and $100 \mu \mathrm{M})$. The water sample was measured using the proposed strategy and ICP-MS three times. The recovery rates were $94.6-106 \%$ and $93.5-104 \%$ for the biosensor and ICP-MS, respectively (Table 1). These experimental results demonstrated the feasibility, accuracy, and practicability of the "turn-off" dual DNAzyme colorimetric biosensor for qualitative analysis in practical samples with little interference.

Table 1. Determination of $\mathrm{Cu}^{2+}$ in water samples using the biosensors and ICP-MS.

\begin{tabular}{cccccc}
\hline Sample & Addition $(\mathbf{n M})$ & Biosensor $(\mathbf{n M})$ & Recovery Rate (\%) & ICP-MS (nM) & Recovery Rate (\%) \\
\hline 1 & 10 & $10.3 \pm 0.3$ & $103 \pm 3$ & $9.9 \pm 0.5$ & $99 \pm 5$ \\
2 & 20 & $20.2 \pm 0.5$ & $101 \pm 2.5$ & $19.4 \pm 0.7$ & $97 \pm 3.5$ \\
3 & 40 & $39.2 \pm 0.7$ & $98 \pm 1.8$ & $38.8 \pm 0.8$ & $97 \pm 2$ \\
4 & 60 & $58.4 \pm 1.6$ & $97.3 \pm 2.7$ & $60.4 \pm 1.9$ & $100.7 \pm 3.2$ \\
5 & 80 & $78.9 \pm 1.4$ & $98.6 \pm 1.8$ & $80.7 \pm 1.6$ & $100.9 \pm 2$ \\
6 & 100 & $99.0 \pm 1.3$ & $99 \pm 1.3$ & $101.2 \pm 2.8$ & $101.2 \pm 2.8$ \\
\hline
\end{tabular}

\section{Materials and Methods}

\subsection{Materials and Reagents}

All of the DNA oligonucleotides used in our study were synthesized by Invitrogen (Life Technologies, Carlsbad, CA, USA) and are listed in Table S1. Exo III was purchased from New England Biolabs, Inc., Ipswich, MA, USA. ABTS; hemin; dimethylsulfoxide (DMSO); $\mathrm{H}_{2} \mathrm{O}_{2}$; tris (hydroxymethyl) aminomethane (Tris); tetramethylethylenediamine (TEMED); ethylenediamine tetraacetic acid disodium salt (EDTA); 4-(2-hydroxyethyl)-1piperazineethanesulfonic acid (HEPES); and the metal salts, including $\mathrm{Cu}\left(\mathrm{NO}_{3}\right)_{2}, \mathrm{Fe}\left(\mathrm{NO}_{3}\right)_{3}$, $\left.\mathrm{Fe}\left(\mathrm{NO}_{3}\right)_{2}, \mathrm{Zn}\left(\mathrm{NO}_{3}\right)_{2}, \mathrm{Mg}\left(\mathrm{NO}_{3}\right)_{2}, \mathrm{~Pb}\left(\mathrm{NO}_{3}\right)_{2}, \mathrm{Hg}\left(\mathrm{NO}_{3}\right)_{2}, \mathrm{Ca}\left(\mathrm{NO}_{3}\right)_{2}, \mathrm{Mn}\left(\mathrm{NO}_{3}\right)_{2}, \mathrm{Ni}\left(\mathrm{NO}_{3}\right)_{2}\right)$, and $\mathrm{KCl}$, were purchased from Sigma Chemical Company (St. Louis, MO, USA).

\subsection{Cu-DNAzyme Activity Assays}

In order to prepare the Cu-DNAzyme complexes, the respective enzyme $(1.5 \mu \mathrm{M})$ and carboxyfluorescein (FAM)-labeled substrate $(1 \mu \mathrm{M})$ were mixed in a buffer $(50 \mathrm{mM}$ HEPES, $1.5 \mathrm{M} \mathrm{NaCl}, 50 \mu \mathrm{M}$ sodium ascorbate, $\mathrm{pH} 7.0$ ) and annealed at $95^{\circ} \mathrm{C}$ for $3 \mathrm{~min}$ followed by slowly cooling to room temperature. In a typical experiment, $1 \mu \mathrm{M}$ annealed $\mathrm{Cu}$-DNAzyme was mixed with $1 \mu \mathrm{M} \mathrm{Cu}^{2+}$ solution in a buffer in order to initiate a cleavage reaction (total $7 \mu \mathrm{L}$ ). At the designated time point, the reaction was quenched by $7 \mu \mathrm{L}$ gel loading buffer ( $8 \mathrm{M}$ urea). The products were analyzed by $15 \%$ denaturing polyacrylamide gel electrophoresis (dPAGE) and imaged by a Bio-Rad ChemiDoc MP imaging system. Then, the intensities of the bands were analyzed by Image Lab 4.1 software.

\subsection{The Procedure of EMCA and Dual-DNAzyme Colorimetric Biosensor}

$\mathrm{A} \mathrm{Cu}^{2+}$-dependent DNAzyme (named CUzyme) was designed to explore the feasibility of EMCA. CUzyme was heated to $95^{\circ} \mathrm{C}$ for $3 \mathrm{~min}$, followed by gradual cooling to room temperature. The experiments were performed with $0.8 \mu \mathrm{M}$ CUzyme, $1.6 \mu \mathrm{M}$ G4-DNAzyme, 4 U Exo III, $1 \times$ NEBuffer 1 (10 mM Bis-Tris-Propane-HCl, $10 \mathrm{mM} \mathrm{MgCl}$, $1 \mathrm{mM}$ DTT, pH 7.0), and $300 \mathrm{nM} \mathrm{Cu}^{2+}$ and incubated for $60 \mathrm{~min}$ at $37^{\circ} \mathrm{C}$. The subsequent reaction products were analyzed by a chromogenic reaction. The assays were performed with $10 \mu \mathrm{L}$ EMCA products, $10 \mu \mathrm{L}$ hemin $(12 \mu \mathrm{M})$, and $80 \mu \mathrm{L}$ enzyme buffer $(10 \mathrm{mmol} / \mathrm{L}$ $\mathrm{NaH}_{2} \mathrm{PO}_{4} / \mathrm{Na}_{2} \mathrm{HPO}_{4}, 100 \mathrm{mmol} / \mathrm{L} \mathrm{KCl}, 2 \mathrm{mmol} / \mathrm{L} \mathrm{MgCl}_{2}, 0.003 \%$ Triton X-100, $\mathrm{pH} 7.0$ ); incubation at $37^{\circ} \mathrm{C}$ for $20 \mathrm{~min}$; and then the addition of $30 \mu \mathrm{L}$ colorimetric buffer was included ( $1 \mathrm{~mL}$ citrate buffer ( $\mathrm{pH} 4.0)$ mixed with $5 \mu \mathrm{L} \mathrm{ABTS} \mathrm{(45} \mathrm{mmol/L)} \mathrm{and} 1 \mu \mathrm{L}$ 
$30 \% \mathrm{H}_{2} \mathrm{O}_{2}$ ). Then, the solution was incubated at room temperature for $5 \mathrm{~min}$, and the absorbance at $412 \mathrm{~nm}$ was measured by using a Thermo Scientific Varioskan Flash (Thermo Scientific, Waltham, MA, USA).

\subsection{Application of the Biosensor in a Real Sample}

Tap water was collected from 6 districts in Beijing, China. The water samples were gently mixed with different concentrations of $\mathrm{Cu}^{2+}$. Then, the samples could be tested directly following the procedures described above.

\section{Conclusions}

In summary, an EMCA-based "turn-off" dual DNAzyme colorimetric biosensor was developed with highly sensitivity and specificity for $\mathrm{Cu}^{2+}$. The proposed strategy combines the advantages of CUzyme, EMCA, and G4-DNAzyme. The CUzyme as a recognition element shows high specificity and cleavage efficiency against other metal ions. The EMCA includes two steps, namely, hybridization and hydrolyzation. First, the remaining CUzyme changes its spatial conformation and drives its assembly with G4-DNAzyme. Second, the assembly products are digested by Exo III to release CUzyme, further driving a new EMCA process. The framework of the signal output in the biosensor is constructed by using G4DNAzyme, which can catalyze the oxidation of ABTS by $\mathrm{H}_{2} \mathrm{O}_{2}$. More sensitive absorbance signal extinction can be achieved through hydrolysis reactions to form a number of free bases. As a result, the signal identification of the CUzyme, the signal extinction of the EMCA, and the signal detection of G4-DNAzyme can provide this biosensor with high levels of selectivity and sensitivity. Moreover, by changing the specific cleavage DNAzymes for other metal ions, this proposed strategy can easily be extended in order conveniently detect many other metal ions and will have wide applications in environmental, water, soil, and food sample analysis.

Supplementary Materials: The following are available online at https://www.mdpi.com/article/ 10.3390/catal11111352/s1, Figure S1: Hydrolyzing reaction of Exo III, Figure S2: Color reaction. Table S1: Oligonucleotides used in this study, Table S2: Comparison among previously reported method for the detection of $\mathrm{Cu}^{2+}$.

Author Contributions: B.Z. and Y.X. designed the experiment; B.Z. wrote the original manuscript; K.H. and H.W. edited the manuscript; D.S. and Y.X. revised, reviewed, and edited the manuscript. All authors have read and agreed to the published version of the manuscript.

Funding: This research was funded by Project supported by the Key R\&D and promotion projects in Henan Province (Grant No. 202102310142), the Key Scientific Research Projects of Colleges and Universities in Henan Province (Grant No. 20A550014), China Postdoctoral Science Foundation (Grant No. 2021M690277), and Open fund for scientific research platform of Zhengzhou Railway Vocational and Technical College (Grant No. 2019KFJJ007).

Acknowledgments: Yuancong Xu would like to thank the Beijing Postdoctoral Research Foundation (2021-ZZ-137).

Conflicts of Interest: The authors declare no conflict of interest.

\section{References}

1. Festa, R.A.; Thiele, D.J. Copper: An essential metal in biology. Curr. Biol. 2011, 21, R877-R883. [CrossRef] [PubMed]

2. Cotruvo, J.J.A.; Aron, A.T.; Ramos-Torres, K.M.; Chang, C.J. Synthetic fluorescent probes for studying copper in biological systems. Chem. Soc. Rev. 2015, 44, 4400-4414. [CrossRef]

3. Säbel, C.E.; Neureuther, J.M.; Siemann, S. A spectrophotometric method for the determination of zinc, copper, and cobalt ions in metalloproteins using Zincon. Anal. Biochem. 2010, 397, 218-226. [CrossRef]

4. Chen, J.; Teo, K.C. Determination of cadmium, copper, lead and zinc in water samples by flame atomic absorption spectrometry after cloud point extraction. Anal. Chim. Acta 2001, 450, 215-222. [CrossRef]

5. Wang, Z.; Jia, N.; Zhou, X.; Han, J.; Bu, H. Cu(I)-Catalyzed Click Reaction-Triggered 3D DNA Walker for Constructing an “OFF-ON" Fluorescent Biosensor for Cu2+ Detection. ACS Appl. Bio Mater. 2021, 4, 3571-3578. [CrossRef] 
6. Tian, J.; Du, Z.; Zhu, L.; Shao, X.; Li, X.; Xu, W. Fluorescent detection of $\mathrm{Cu}$ (II) ions based on DNAzymatic cascaded cyclic amplification. Microchim. Acta 2020, 187, 443. [CrossRef]

7. Stebunov, Y.V.; Yakubovsky, D.I.; Fedyanin, D.Y.; Arsenin, A.V.; Volkov, V.S. Superior Sensitivity of Copper-Based Plasmonic Biosensors. Langmuir 2018, 34, 4681-4687. [CrossRef] [PubMed]

8. Safran, V.; Göktürk, I.; Derazshamshir, A.; Yılmaz, F.; Sağlam, N.; Denizli, A. Rapid sensing of $\mathrm{Cu}^{+2}$ in water and biological samples by sensitive molecularly imprinted based plasmonic biosensor. Microchem. J. 2019, 148, 141-150. [CrossRef]

9. Korkmaz, N.; Hwang, C.; Kessler, K.K.; Silina, Y.E.; Müller, L.; Park, J. A novel copper (II) binding peptide for a colorimetric biosensor system design. Talanta 2021, 232, 122439. [CrossRef]

10. Aktara, M.N.; Das, S.; Nayim, S.; Sahoo, N.K.; Beg, M.; Jana, G.C.; Maji, A.; Jha, P.K.; Hossain, M. A sensorial colorimetric detection method for $\mathrm{Hg}^{2+}$ and $\mathrm{Cu}^{2+}$ ions using single probe sensor based on 5-methyl-1,3,4-thiadiazole-2-thiol stabilized gold nanoparticles and its application in real water sample analysis. Microchem. J. 2019, 147, 1163-1172. [CrossRef]

11. Liu, K.; Chen, K.S.; Sen, D.; Yu, H.-Z. Ultrasensitive detection of total copper with an electrochemical biosensor built on the in cis coupling of hexynyl CLICK-17 DNAzyme with azido self-assembled monolayers. Electrochim. Acta 2021, 379, 138125. [CrossRef]

12. Xu, W.; Zhu, L.; Shao, X.; Huang, K.; Luo, Y. An electrochemical biosensor based on nucleic acids enzyme and nanochannels for detecting copper (II) ion. Biosens. Bioelectron. 2018, 120, 168-174. [CrossRef] [PubMed]

13. Atapour, M.; Amoabediny, G.; Ahmadzadeh-Raji, M. Integrated optical and electrochemical detection of $\mathrm{Cu}^{2+}$ ions in water using a sandwich amino acid-gold nanoparticle-based nano-biosensor consisting of a transparent-conductive platform. RSC Adv. 2019, 9, 8882-8893. [CrossRef]

14. Cuenoud, B.; Szostak, J.W. A DNA metalloenzyme with DNA ligase activity. Nature 1995, 375, 611-614. [CrossRef] [PubMed]

15. Dou, Z.; Zhang, W.; Du, Q.; Liu, G. An in-situ plasmonic spectroscopy based biosensor for detection of copper (II) ions highlighting analytical specifications. Sensor. Actuat. B Chem. 2021, 329, 129103. [CrossRef]

16. Song, X.; Wang, Y.; Liu, S.; Zhang, X.; Wang, J.; Wang, H.; Zhang, F.; Yu, J.; Huang, J. A triply amplified electrochemical lead(II) sensor by using a DNAzyme and via formation of a DNA-gold nanoparticle network induced by a catalytic hairpin assembly. Microchim. Acta 2019, 186, 559. [CrossRef]

17. Fu, L.; Lu, Q.; Liu, X.; Chen, X.; Wu, X.; Xie, S. Combining whispering gallery mode optofluidic microbubble resonator sensor with GR-5 DNAzyme for ultra-sensitive lead ion detection. Talanta 2020, 213, 120815. [CrossRef]

18. Li, W.; Yang, Y.; Chen, J.; Zhang, Q.; Wang, Y.; Wang, F.; Yu, C. Detection of lead(II) ions with a DNAzyme and isothermal strand displacement signal amplification. Biosens. Bioelectron. 2014, 53, 245-249. [CrossRef] [PubMed]

19. Li, S.; Zhu, L.; Li, G.; Du, Z.; Tian, J.; Luo, Y.; Huang, K.; Xu, W. A “turn-off” ultra-sensitive fluorescent quantitative biosensor driven by zinc ion DNAzyme. Sensor. Actuat. B Chem. 2019, 285, 173-178. [CrossRef]

20. Li, S.; Li, G.; Du, Z.; Zhu, L.; Tian, J.; Luo, Y.; Huang, K.; Xu, W. The ultra-sensitive visual biosensor based on thermostatic triple step functional nucleic acid cascade amplification for detecting $\mathrm{Zn}^{2+}$. Food Chem. 2019, 290, 95-100. [CrossRef]

21. Zhao, X.-H.; Zhang, L.-Z.; Zhao, S.-Y.; Cui, X.-H.; Gong, L.; Zhao, R.; Yu, B.-F.; Xie, J. Silver-ion-mediated Mg²+-dependent DNAzyme activity for amplified fluorescence detection of cysteine. Analyst 2019, 144, 1982-1987. [CrossRef]

22. Wang, X.; Zeng, R.; Chu, S.; Tang, W.; Lin, N.; Fu, J.; Yang, J.; Gao, B. A quencher-free DNAzyme beacon for fluorescently sensing uranyl ions via embedding 2-aminopurine. Biosens. Bioelectron. 2019, 135, 166-172. [CrossRef] [PubMed]

23. Zhu, L.; Miao, M.; Shao, X.; Du, Z.; Huang, K.; Luo, Y.; Xu, W. A Universal Electrochemical Biosensor Using Nick-HCR Nanostructure as Molecular Gate of Nanochannel for Detecting Chromium(III) Ions and MicroRNA. Anal. Chem. 2019, 91, 14992-14999. [CrossRef] [PubMed]

24. Chen, X.; Wang, X.; Lu, Z.; Luo, H.; Dong, L.; Ji, Z.; Xu, F.; Huo, D.; Hou, C. Ultra-sensitive detection of Pb ${ }^{2+}$ based on DNAzymes coupling with multi-cycle strand displacement amplification (M-SDA) and nano-graphene oxide. Sens. Actuat. B Chem. 2020, 311, 127898. [CrossRef]

25. Tang, D.; Xia, B.; Tang, Y.; Zhang, J.; Zhou, Q. Metal-ion-induced DNAzyme on magnetic beads for detection of lead(II) by using rolling circle amplification, glucose oxidase, and readout of $\mathrm{pH}$ changes. Microchim. Acta 2019, 186, 318. [CrossRef] [PubMed]

26. Liu, J.; Hu, Q.; Qi, L.; Lin, J.-M.; Yu, L. Liquid crystal-based sensing platform for detection of $\mathrm{Pb}^{2+}$ assisted by DNAzyme and rolling circle amplification. J. Hazard. Mater. 2020, 400, 123218. [CrossRef]

27. Zhou, F.; Li, B. Exonuclease III-Assisted Target Recycling Amplification Coupled with Liposome-Assisted Amplification: One-Step and Dual-Amplification Strategy for Highly Sensitive Fluorescence Detection of DNA. Anal. Chem. 2015, 87, 7156-7162. [CrossRef]

28. Bayindir, S.; Toprak, M. A novel pyrene-based selective colorimetric and ratiometric turn-on sensing for copper. Spectrochim. Acta. A 2019, 213, 6-11. [CrossRef]

29. Zhu, X.; Duan, Y.; Li, P.; Fan, H.; Han, T.; Huang, X. A highly selective and instantaneously responsive Schiff base fluorescent sensor for the "turn-off" detection of iron(iii), iron(ii), and copper(ii) ions. Anal. Methods 2019, 11, 642-647. [CrossRef]

30. Yang, H.; Zhou, Y.; Liu, J. G-quadruplex DNA for construction of biosensors. TrAC Trends Anal. Chem. 2020, 132, 116060. [CrossRef] 